doi:10.12662/2359-618xregea.v9i1.p74-92.2020

ARTIGOS

\section{INFLUÊNCIA DAS REDES SOCIAIS NO PROCESSO DE DECISÃO DE COMPRA DO CONSUMIDOR}

\author{
THE INFLUENCE OF SOCIAL NETWORKS ON \\ CONSUMER PURCHASE DECISION
}

\section{RESUMO}

As redes sociais vêm desenvolvendo um importante papel no marketing e têm provocado mudanças no comportamento do consumidor ao exercer influências no processo de compra de um bem ou serviços. A pesquisa se propôs a investigar as influências das redes sociais no processo de decisão dos consumidores das óticas. Para a realização do estudo, foi utilizada uma metodologia de caráter descritivo com abordagem quantitativa e coleta dos dados, por meio de aplicação de 210 questionários com os consumidores das óticas de Pau dos Ferros/RN. A análise dos resultados deu-se por meio de testes e métodos de análises estatísticos, qual seja, Teste de Bartlett e KMO, Cronbach Alpha, teste t de Student e a análise fatorial. Nos resultados, constatou-se que os consumidores de óticas são influenciados pelo conteúdo que eles visualizam nas principais redes sociais (facebook e whatsapp) e, principalmente, quando alguma variável acerca da qualidade do produto, preço, marca, propaganda e indicação de familiares e amigos está presente nas postagens.

Palavras-chave: Web 2.0. Redes Sociais. Comportamento do Consumidor.

\footnotetext{
Mercia Cristiley Barreto Viana profamerciac@gmail.com Mestra em AdministraçãoUnP/Natal-RN. Graduada em Administração - UERN/ Mossoró-RN. Coordenadora do Curso de Administração da Faculdade Católica do Rio Grande do Norte. Mossoró $R N-B R$.

Maria Eleneide da Paiva da Silva elineide-paiva@hotmail.com>. Graduada em Administração UERN/CAMEAM-RN. Mossoró - $R N-B R$.
}

\begin{abstract}
Social networks have been developing an important role in marketing and have caused changes in consumer behavior by influencing the process of buying a good or services. The research aimed to investigate the influences of social networks in the decision-making process of optical consumers. For the accomplishment of the study, a descriptive methodology was used with a quantitative approach and data collection, through the application of 210 questionnaires with consumers of Pau dos Ferros / RN optics. The results were analyzed through tests and methods of statistical analysis, namely, Bartlett and KMO test, Cronbach Alpha, Student's $t$ test and factor analysis. In the results, it was found that optics consumers are influenced by the content they view on the
\end{abstract}


main social networks (Facebook and Whatapp) and especially when some variable about product quality, price, brand, advertising and referral of family and friends is present in the posts.

Keywords: Web 2.0. Social networks. Consumer behavior.

\section{INTRODUÇÃO}

A abordagem deste estudo visa investigar as influências das redes sociais no processo de decisão de compra dos consumidores das óticas de Pau dos Ferros. Para tanto, as redes sociais proporcionam efeitos positivos e negativos dos produtos ou serviços, uma vez que o efeito que as novas mídias exercem no comportamento dos consumidores ganhou novas proporções nesses indivíduos e possibilitou que eles se manifestassem, espontaneamente, por meio de reclamações, formação de opinião pública, preferências, experiências positivas e/ou negativas de consumo relacionadas aos produtos e serviços adquiridos ou testados (SOLOMON, 2016). Diante do cenário atual, a web 4.0 vem desempenhando um papel importante não só no marketing, como também no relacionamento entre as empresas e seus consumidores. $\mathrm{O}$ grande desafio para as organizações e os profissionais de marketing é compreender melhor a natureza das mudanças provocadas por essas novas mídias e das tendências no comportamento de compra, além dos fatores que alteram os padrões de competitividade dos mercados de forma geral.

Nesse contexto, aproximadamente, dez anos atrás, Saad, Abreu e Ramos (2009) apontam as principais mídias sociais da atualidade, como blogs, redes sociais, sistemas de compartilhamento de fotos e vídeos, sistemas de notícias e salas de bate-papo se sobressaem. De acordo com os autores, essas ferramentas oferecem aos usuários recursos que estimulam e incentivam a ação coletiva em redes sociais como o Facebook, MySpace, Linkedin, Orkut, Twitter, WhatsApp, Blog entre outras que são iniciativas privadas autônomas e que objetivam agregar usuários, além de promover ações co- merciais com foco nessa audiência. Atualmente, de acordo com a pesquisa realizada pelo Rock Content (2018), o MySpace e Orkut foram instintos; além disso, cerca de $94 \%$ das organizações públicas e privadas estão presentes nas redes sociais, bem como foram apresentados, como resultado desta pesquisa, os benefícios que as redes sociais trazem, como a divulgação da marca da empresa $(78,1 \%)$, a ampliação em números de vendas e o aumento o número de clientes (51\%) (ROCK CONTENT, 2018).

Diante do exposto, constatou-se a importância da identificação e da análise das influências que as novas mídias exercem no processo da tomada de decisão, bem como as tendências nos comportamentos de compras, para que as organizações possam desenvolver estratégias voltadas para essa nova realidade. Portanto, investigar as influências das redes sociais no processo de decisão de compra dos consumidores das óticas de Pau dos Ferros é o proposito deste trabalho. O referencial teórico apresenta-se divido por tópicos como: Web, Web 1.0, Web 2.0, 3.0 e 4.0 redes sociais, Facebook, Instagram, Twitter, WhatsApp, Blog, redes sociais no Brasil, comportamento do consumidor, influências no comportamento do consumidor, tipos de tomadas de decisão, decidindo e avaliando a compra e o comportamento do consumidor online.

\section{FUNDAMENTAÇÃO TEÓRICA}

\subsection{WEB}

A internet originou-se na década de 1960 mediante pesquisas militares americanas durante a Guerra Fria, mas a sua expansão começou apenas por volta da década de 1990 quando Tim Berners Lee deu início a uma rede mundial composta por um sistema de distribuição da internet, para ser utilizado por grupos de pesquisadores. Entretanto, com o tempo, foi adotado por outros, o que resultou em um consórcio que ficou conhecido como Worl Wide Web $(W W W)$, ao qual Reedy e Schullo (2007) a descreve como sendo um sistema de informação em hipermídia. De acordo com Berners-Lee (2000), a Web 
tinha como objetivo final melhorar a existência dos utilizadores por meio da integração e da colaboração entre si, o que de fato aconteceu, visto que a sua rápida expansão permitiu o acesso de novos usuários às informações que ali se encontravam disponíveis. Contudo, a internet e a web ainda não eram um ambiente agradável, pois continham muitos textos e interfaces complexas, gerando, assim, um incômodo aos usuários, mas, no ano de 1994, esse problema foi amenizado com o lançamento do Mosaic, "um aplicativo que simplifica o acesso à web" (REEDY; SCHULLO, 2007, p. 112). Durante uma sessão de brainstorming no evento FOO Camp, em uma conferência na O'Reilly Media, foi desenvolvido um mapa de noções web. Diante do exposto, Trein e Schlemmer (2008) fazem um comparativo das principais características da Web 1.0 e Web 2.0 no quadro 1. propõe se comportar como um inteligente modelo de soluções concretas para aquilo que o usuário precisa (KOLLMAN, 2018).

\subsection{REDES SOCIAIS}

Uma das principais necessidades do ser humano é a da socialização, e essa, por sua vez, pode ser realizada de várias formas - face a face, ligação, redes sociais, e-mail, carta - entre elas, estão as redes sociais, que se tem tornado, aos poucos, um dos maiores veículos de comunicação da atualidade. Essa comunicação é realizada por meio de ferramentas que possibilitam a interação entre seus usuários mesmo estando longe. De acordo com Recuero (2009), uma rede social é composta por um conjunto de dois elementos: atores (pessoas, instituições ou grupos) e suas conexões (interações ou la-

Quadro 1 - Principais características da web 1.0 e web 2.0

\begin{tabular}{|c|c|}
\hline Web 1.0 & Web 2.0 \\
\hline Publicação & Participação \\
\hline Input - output & Processo - Troughput (Primo, 2000) \\
\hline Páginas pessoais & Atitude \\
\hline Tecnologia & Webtop - disco remoto \\
\hline Desktop - disco rígido & Plataforma Web \\
\hline Navegador & Interfaces amigáveis \\
\hline Sistemas complexos & Todos - Todos \\
\hline Um - Um & Sociedade do conhecimento \\
\hline Sociedade da Informação & Interação mútua (Primo, 2000) \\
\hline Interação relativa (Primo, 2000) & XML \\
\hline HTML & Heterárquico \\
\hline Hierárquico & Autônomo \\
\hline Controle de conteúdo & \\
\hline Reflexivo & Conão coletiva e colaborativa - autoria \\
\hline
\end{tabular}

Fonte: (TREIN; SCHLEMMER, 2008, p. 4).

A Web 3.0 é considerada a web semântica que dá uma guinada na educação usando interfaces inteligentes (AGHAEI; EMATBAKHSH; FARSANI, 2012). O Web 4.0 oferece um novo modelo de interação do usuário com o mais abrangente e personalizado, não se limitando apenas a exibir informações, mas ços sociais). Por meio da rede social, as pessoas podem criar ligações com outros usuários da rede, estabelecendo laços sociais, e partilhando informações sobre temas variados.

Segundo Kabadayi e Price (2014), os resultados têm várias implicações para os gestores em relação às suas estratégias de mídia social 
e dar-lhes orientação para alcançar um melhor envolvimento do cliente no Facebook. A fácil compreensão dos fatores que afetam os usuários do Facebook ou comportamento considerado útil para os profissionais que pretendem usar o Facebook como parte de sua estratégia competitiva, por meio do marketing.

Mainieri e Ribeiro (2011) afirmam que as mídias sociais só serão capazes de contribuir no processo de comunicação, quando passarmos a considerar a existência de um sujeito ativo nesse processo, que é capaz de analisar as informações recebidas, assim como também assumir o papel de emissor da comunicação. Portanto, enquanto sujeito de um processo social, tornar-se-á parte do processo de comunicação pública.

\subsection{COMPORTAMENTO DO CONSU- MIDOR}

Para Churchill e Peter (2000, p. 146), "consumidores são pessoas que compram bens e serviços para si mesmas ou para outros, e não para revendê-los ou usá-los como insumos", ou seja, eles buscam bem mais do que apenas adquirir um produto ou serviço e, sim, a satisfação, uma necessidade ou o desejo, e tais necessidades podem surgir por meio de estímulos internos e externos, em forma de motivação, ao qual o consumidor busca atendê-la de forma impulsiva. Segundo Foxall (2005, p. 88), "comportamento do consumidor inclui quaisquer atividades de pré-compra ou pós-compra que são relevantes para o gerenciamento do marketing." As atividades ligadas à pré-compra seriam as que geram a crescente conscientização de uma necessidade ou desejo e busca de produtos para satisfazê-la. Por sua vez, as atividades de pós-compra estão relacionadas às avaliações realizadas após a obtenção de um produto, é nesse ponto que o consumidor tem suas expectativas atingidas ou não. Essas experiências (positivas ou negativas) influenciam na compra repetida do produto de uma determinada marca, como também a repercussão que o relato dele terá com demais consumidores.
Segundo Kotler e Keller (2006, p. 183), a teoria de Freud "conclui que as forças psicológicas que formam o comportamento dos indivíduos são basicamente inconscientes e que ninguém chega a atender por completo as próprias motivações." Pois, quando uma pessoa avalia um determinado produto, ela reage não apenas aos fatores visuais, mas também a outros sinais menos conscientes, uma vez que, para cada tipo de produto, existe uma variedade de motivos pelos quais o consumidor desejará adquiri-lo. Abraham Maslow era um psicólogo que desenvolveu uma teoria na qual se buscava "explicar por que os indivíduos são motivados por necessidades específicas em determinados momentos." (KOTLER; KELLER, 2006, p. 183). Na teoria de Maslow, eram as necessidades não atendidas que motivavam as pessoas a agirem, logo ele as classificou em uma hierarquia, contendo cinco níveis que iam da necessidade mais urgente (fisiológicas), para a menos urgente (segurança, sociais, estima e auto realização).

De acordo Schultz e Peltier (2013), os gestores empresariais estão interessados em aprender como as mídias sociais podem beneficiar (ou prejudicar) o envolvimento do consumidor em relação às atividades comerciais, as quais nem sempre são bem-vindas em todos os espaços das mídias sociais. Nesse comentário, os autores pretendem esboçar os desafios que os meios sociais enfrentam para realçar o acoplamento do consumidor e a compra. Depois do surgimento de uma necessidade, faz-se necessário que o consumidor busque informações de como supri-la. Logo, partindo do princípio dessas fontes, os consumidores irão conhecer várias marcas de um mesmo produto que poderão suprir suas necessidades.

\subsubsection{Influências no comportamento do consumidor}

Partindo do pressuposto de que entender o comportamento do consumidor e o seu processo de compra é algo complexo. Nesta parte do trabalho, serão abordadas as principais influências existentes nesse processo. Logo, Kotler e 
Keller (2006, p. 172) afirmam que o "comportamento de compra do consumidor é influenciado por fatores culturais, sociais, pessoais e psicológicos, sendo que os culturais exercem a maior e mais profunda influência". Churchill e Peter (2000) reforçam esse pensamento quando afirmam que os grupos de cultura, subcultura e classe social influenciam o comportamento ao transmitirem mensagens diretas ou indiretas a respeito de atividades específicas. A figura 1 apresenta, de forma detalhada, todos os fatores que influenciam no processo de tomada de decisão do consumidor. principal ponto de atração (influência) por parte do usuário da internet como veículo de compra. Para tanto, associa-se aos fatores que influenciam no processo de tomada de decisão de compra do consumidor; porém, tornando mais divertida aquisição, por meio das redes sociais (KOTLER; KELLER, 2006).

\subsubsection{Tipos de tomadas de decisão}

O processo de tomada de decisão possui etapas que nem sempre são seguidas pelos consumidores, pois o que determina está di-

Figura 1 - Fatores que influenciam no processo de tomada de decisão do consumidor

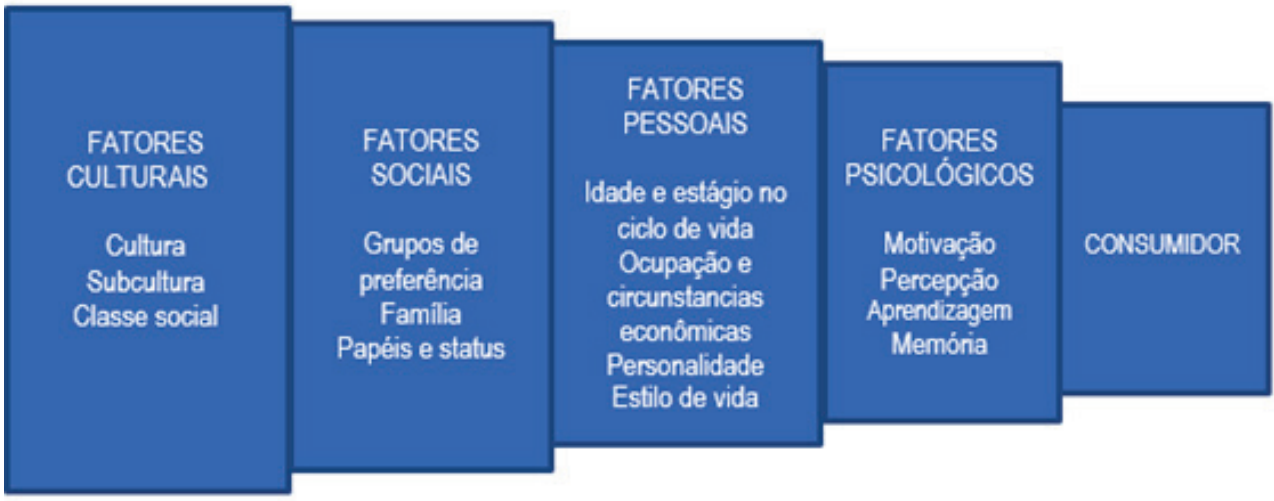

Fonte: adaptado de Kotler, Kartajaya e Setiawan (2017).

Segundo Baxter (2014), uma das principais conclusões que surgiram das suas pesquisas é a que indica a importância de rever os fatores sociais e culturais nas organizações, em relação à introdução da Web 2.0 no local de trabalho. Além de avaliar as questões técnicas que podem impactar sobre a aplicação da $\mathrm{Web}$ 2.0 nas organizações, no entanto, a diversão é o retamente ligado ao grau de importância que a compra possui em determinado momento. Sendo assim, o consumidor pode vir a adquirir um produto de acordo com a representatividade que ele possui e não por seu valor. Para tanto, são apresentados três tipos de tomada de decisões de consumidores: rotineira, limitada e extensiva, conforme quadro 2.

Quadro 2 - Características de três tipos de tomadas de decisões dos consumidores

\begin{tabular}{|c|c|c|c|c|}
\hline Tipo de decisão & $\begin{array}{c}\text { Envolvimento } \\
\text { do consumidor } \\
\text { com a compra }\end{array}$ & $\begin{array}{c}\text { Características do conjunto } \\
\text { considerado }\end{array}$ & $\begin{array}{c}\text { Fontes de } \\
\text { informações } \\
\text { consultadas }\end{array}$ & $\begin{array}{c}\text { Tempo } \\
\text { investido }\end{array}$ \\
\hline Rotineira & Baixo & $\begin{array}{c}\text { Poucas opções de marcas, } \\
\text { vendedores e caraterísticas de } \\
\text { produtos avaliados }\end{array}$ & $\begin{array}{c}\text { O mínimo } \\
\text { possível }\end{array}$ \\
\hline Limitada & Moderado & $\begin{array}{c}\text { Várias marcas, vendedores e } \\
\text { características de produtos avaliados }\end{array}$ & $\begin{array}{c}\text { Internas e algumas } \\
\text { externas }\end{array}$ & Pouco \\
\hline Extensiva & Alto & $\begin{array}{c}\text { Muitas marcas, vendedores } \\
\text { e características de produtos } \\
\text { avaliados }\end{array}$ & $\begin{array}{c}\text { Algumas internas } \\
\text { e muitas externas }\end{array}$ & Muito \\
\hline
\end{tabular}


Depois de identificar as necessidades, buscar informações e avaliar as alternativas possíveis, o consumidor estará pronto para fazer uma compra, mas essa etapa inclui uma decisão, e para sua realização, faz-se necessário o questionamento de quatro perguntas: "o quê, onde, quando comprar e como pagar." (CHURCHILL; PETER, 2000, p. 150).

\subsubsection{Comportamento do consumidor online}

Um dos estudos realizados destaca a conveniência e a economia de tempo, a variedade de opções, a qualidade das informações que podem ser vistas na tela do computador e a diversão como os principais pontos de atração do uso da internet como veículo de compra (GIGLIO, 2005). A insegurança na utilização de cartões de créditos e a manutenção da privacidade são as principais preocupações no ambiente virtual (LADEIRA, 2000).

Em um dos seus estudos empíricos, Caro (2005) investigou quais fatores são críticos na adoção da compra pela internet e obteve como resultado as variáveis: envolvimento, inovatividade e facilidade. $\mathrm{O}$ estudo pressupõe que as pessoas inovadoras sejam mais perfeccionistas e busquem, de forma consciente, por produtos de alta qualidade, marca, preços que correspondam à qualidade do produto, os quais estão voltados para a satisfação consigo mesmo. Outros aspectos importantes a serem considerados em uma compra são informações, rapidez, economia de tempo e segurança.

Morgado (2003, p. 15) buscou explicar o comportamento de compras online a partir de três grandes grupos de variáveis encontradas, frequentemente, na literatura referente a esse tema: o perfil do consumidor, o uso que se faz na internet e atitudes. Como pontos principais do seu estudo, destacam-se a caracterização do consumidor online como aquele que, em relação aos não compradores, tem nível socioeconômico superior, valoriza mais a conveniência, tem maior tendência à inovação, menor aversão ao risco e menor orientação experimental (não necessita ver e tocar no produto antes de comprá-lo), está há mais tempo utilizando a internet, acessa de vários locais, confia mais na segurança da rede e a vê como uma mídia mais divertida e útil.

Diante do exposto, surgiu o seguinte questionamento, com base no estudo teórico realizado: será que as redes sociais influenciam positivamente no processo de decisão de compra do consumidor em óticas? Essa questão-problema é justificada por Sharma e Rehman (2013). A adoção da rede social deve ser vista como uma mudança cultural e comportamental dentro da organização para envolver-se, de forma transparente com clientes que não têm medo de expressar suas opiniões e são grandes influenciadores de suas redes conectadas. As redes sociais podem ser visualizadas pelo computador celular, tablete; entre outros eletrônicos, poderá haver influência. Ladeira (2000). No entanto, a diversão é o principal ponto de atração (influência) por parte do usuário da internet como veículo de compra. Para tanto, associa-se aos fatores que influenciam no processo de tomada de decisão de compra do consumidor, porém, tornando mais divertida a aquisição, por meio das redes sociais (KOTLER; KELLER, 2006).

\section{PROCEDIMENTOS ME- TODOLÓGICOS}

O universo deste estudo foi constituído de 20 óticas da cidade de Pau dos Ferros - RN; para tanto, a amostra realizada para esta pesquisa foram as 06 maiores óticas, cuja receita bruta total, no ano-calendário anterior, tenha sido igual ou inferior a R\$ 48.000.000,00 (quarenta e oito milhões de reais) Sebrae (2017), sendo assim, optou-se por analisar seus consumidores em relação à decisão de compra por meio das redes sociais. Segundo Hair Junior et al. (2009), o cálculo determinado para a amostragem da pesquisa é baseado no tamanho da amostra mínima que corresponde a um número de 5 a 10 vezes o quantitativo das variáveis da maior teoria estudada. A coleta de dados foi realizada, por meio, de um questionário on line via Internet, redes sociais como Whatsapp, Facebook, utilizando a escala likert de cinco pontos. Por se tratar de uma pesquisa com abordagem predominante- 
mente quantitativa, foram utilizados testes e métodos de análises estatísticos, a saber, Cronbach's Alpha, teste t de Student e testes de KMO e esfericidade de Bartlett e Análise fatorial. Para a aplicação de testes estatísticos, utilizou-se o software SPSS, versão 20.0.

Para a obtenção dos dados, foi realizada uma pesquisa de caráter quantitativo e utilizou-se uma amostra 210 consumidores, baseada no tamanho da amostra mínima que corresponde a um número de 5 a 10 vezes o quantitativo das variáveis da maior teoria estudada, por meio da utilização do método de modelagem de equações estruturais mínimas quadradas parciais (HAIR JUNIOR et al., 2009). Aplicou-se um questionário que englobava as variáveis que influenciavam no processo de tomada de decisão do consumidor destacadas por Kotler e Keller (2006) e Churchill e Peter (2000) no referencial teórico do presente trabalho.

\section{ANALISES E DISCUSSÕES DOS RESULTADOS}

\subsection{CONFIABILIDADE DOS DADOS}

Apresentam-se os 24 itens utilizados nos questionários aplicados, que foram analisados por meio do teste estatístico de Cronbach's Alpha para sua verificação de confiabilidade. Me- diante o teste estatístico Cronbach 's Alpha, que verifica a confiabilidade dos dados, pode-se observar que todos os 24 itens avaliados quanto ao questionário aplicado, respectivamente, obtiveram um alfa de Cronbach's acima de 0,80 , ou seja, consistência dos dados classificada como satisfatória para o instrumento de pesquisa. A partir desse resultado, foi realizado um teste de validação do instrumento de pesquisa, a saber, no próximo tópico.

\subsection{VALIDAÇÃO DO QUESTIONÁRIO}

O instrumento de coleta foi um questionário sobre a influência das redes sociais na intenção de compra do consumidor de óticas em Pau dos Ferros; foi composto por 24 perguntas fechadas, aplicadas com os clientes de lojas de óticas. Para validação do instrumento de pesquisa, utilizou-se da técnica de análise fatorial; entretanto, inicialmente, foi necessário verificar a existência de níveis de correlação aceitáveis entre as variáveis (qualidade do produto, preço, marca, propaganda e indicação de familiares e amigos) para maior confiabilidade no resultado da análise, cuja adequação da análise fatorial foi confirmada por meio dos testes de KMO e esfericidade de Bartlett, possibilitando verificar a adequação dos dados à aplicação da análise fatorial, conforme tabela 1.

Tabela 1 - Teste de esfericidade de Bartlett e KMO

Teste de esfericidade de Bartlett: Estatística do teste $=2073,969 ; \mathrm{GL}=276$; Valor-p $=0,000$

$$
\mathrm{KMO}=0,831
$$

Fonte: dados da pesquisa (2018).

Por meio do teste de esfericidade de Bartlett, que verifica a presença de correlações entre as variáveis, para um nível de significância de $5 \%$, temos evidência estatística de correlação entre as variáveis estudadas. O teste de $\mathrm{KMO}$, que verifica o grau de intercorrelações entre as variáveis, gerou um valor de 0,831 , o que implica uma boa adequação dos dados à análise fatorial, pois o KMO é um índice utilizado para avaliar a adequação da análise fatorial. Os valores altos devem estar entre $0,5 \mathrm{e}$
1,0 (HAIR JUNIOR et al., 2009). Os valores obtidos nesse teste variam entre 0 e 1 , quanto mais próximo de 1 , mais adequada é a amostra com relação à aplicação da análise fatorial nas questões em estudo (FERREIRA JÚNIOR; BAPTISTA; LIMA, 2004).

Esse resultado é satisfatório, pois o critério de percentagem da variância sugere que uma explicação mínima de $60 \%$ da variabilidade seja suficiente. Conforme tabela 2. 
Tabela 2 - Autovalor e percentual da variância explicada

\begin{tabular}{|c|c|c|c|c|}
\hline Fator & Autovalor & $\begin{array}{l}\text { \% Variância } \\
\text { explicada }\end{array}$ & $\begin{array}{l}\text { Autovalor } \\
\text { acumulado }\end{array}$ & $\begin{array}{c}\text { \% Variância explicada } \\
\text { acumulada }\end{array}$ \\
\hline 1 & 6,62 & 27,58 & 6,62 & 27,58 \\
\hline 2 & 2,27 & 9,45 & 8,89 & 37,03 \\
\hline 3 & 1,97 & 8,22 & 10,86 & 45,25 \\
\hline 4 & 1,46 & 6,08 & 12,32 & 51,33 \\
\hline 5 & 1,29 & 5,36 & 13,61 & 56,69 \\
\hline 6 & 1,13 & 4,54 & 14,74 & 61,24 \\
\hline 7 & 0,99 & 4,30 & 15,73 & 65,53 \\
\hline 8 & 0,95 & 3,95 & 16,68 & 69,49 \\
\hline 9 & 0,83 & 3,47 & 17,51 & 72,96 \\
\hline 10 & 0,76 & 3,18 & 18,27 & 76,14 \\
\hline 11 & 0,71 & 2,97 & 18,98 & 79,11 \\
\hline 12 & 0,64 & 2,66 & 19,62 & 81,77 \\
\hline 13 & 0,61 & 2,55 & 20,23 & 84,32 \\
\hline 14 & 0,55 & 2,29 & 20,78 & 86,61 \\
\hline 15 & 0,50 & 2,10 & 21,28 & 88,71 \\
\hline 16 & 0,46 & 1,90 & 21,74 & 90,61 \\
\hline 17 & 0,44 & 1,82 & 22,18 & 92,43 \\
\hline 18 & 0,37 & 1,54 & 22,55 & 93,97 \\
\hline 19 & 0,34 & 1,40 & 22,89 & 95,38 \\
\hline 20 & 0,29 & 1,22 & 23,18 & 96,60 \\
\hline 21 & 0,27 & 1,11 & 23,45 & 97,71 \\
\hline 22 & 0,25 & 1,03 & 23,70 & 98,74 \\
\hline 23 & 0,16 & 0,68 & 23,86 & 99,43 \\
\hline 24 & 0,14 & 0,57 & 24,00 & 100,00 \\
\hline
\end{tabular}

Fonte: dados pesquisa (2018).

O critério de decisão do número de fatores utilizado a ser selecionado para representar a estrutura latente dos dados foi o de raiz latente, o qual seleciona apenas os fatores que os autovalores são superiores a 1. Sendo assim, observamos, na tabela 2, que 6 fatores são selecionados, correspondendo a $61,24 \%$ da variabilidade total.

Com base nos autovalores, determinamos os autovetores que constituem a obtenção dos fatores. Por meio deles, temos a combinação linear das variáveis originais, dando ori- gem às cargas fatoriais. Na tabela 3 , são apresentadas as cargas fatoriais que representam a contribuição de cada variável para a composição do fator. Utilizando rotação Varimax (8 interações) dos fatores para identificar as cargas fatoriais representativas em cada fator. 


\begin{tabular}{c|c|c|c|c|c|c}
\hline \multicolumn{7}{c}{ Tabela 3 - Cargas fatoriais na composição dos fatores } \\
\hline Questões & Fator 1 & Fator 2 & Fator 3 & Fator 4 & Fator 5 & Fator 6 \\
\hline Q1 & $\mathbf{0 , 8 0}$ & 0,04 & 0,23 & 0,20 & 0,11 & $-0,03$ \\
Q2 & $\mathbf{0 , 7 8}$ & 0,00 & 0,16 & 0,32 & $-0,02$ & $-0,05$ \\
Q3 & $\mathbf{0 , 7 6}$ & $-0,03$ & 0,04 & 0,13 & 0,07 & 0,02 \\
Q4 & $\mathbf{0 , 7 6}$ & 0,20 & 0,37 & 0,27 & $-0,14$ & $-0,29$ \\
Q5 & 0,38 & $\mathbf{0 , 6 8}$ & 0,04 & 0,23 & 0,09 & $-0,05$ \\
Q6 & 0,40 & $\mathbf{0 , 6 4}$ & 0,00 & 0,12 & $-0,09$ & $-0,04$ \\
Q7 & 0,18 & $\mathbf{0 , 7 4}$ & 0,07 & 0,04 & $-0,10$ & 0,24 \\
Q8 & 0,02 & $\mathbf{0 , 7 2}$ & 0,21 & 0,11 & 0,10 & $-0,19$ \\
Q9 & $-0,11$ & $\mathbf{0 , 6 0}$ & 0,35 & 0,19 & 0,18 & 0,13 \\
Q10 & 0,23 & 0,08 & $\mathbf{0 , 8 4}$ & 0,13 & $-0,04$ & 0,05 \\
Q11 & 0,12 & 0,20 & $\mathbf{0 , 8 4}$ & $-0,07$ & 0,04 & 0,02 \\
Q12 & 0,19 & 0,13 & $\mathbf{0 , 7 9}$ & $-0,11$ & 0,06 & $-0,04$ \\
Q13 & 0,17 & 0,13 & $\mathbf{0 , 7 8}$ & $-0,03$ & 0,09 & $-0,03$ \\
Q14 & 0,29 & $-0,11$ & 0,20 & $\mathbf{0 , 7 7}$ & 0,10 & 0,05 \\
Q15 & 0,25 & 0,01 & 0,14 & $\mathbf{0 , 8 4}$ & 0,11 & 0,03 \\
Q16 & 0,06 & 0,09 & 0,06 & $\mathbf{0 , 5 2}$ & 0,50 & $-0,18$ \\
Q17 & 0,15 & 0,30 & $-0,08$ & 0,14 & $\mathbf{0 , 7 2}$ & 0,19 \\
Q18 & 0,10 & 0,29 & $-0,01$ & $-0,30$ & $\mathbf{0 , 5 3}$ & 0,37 \\
Q19 & 0,34 & 0,05 & 0,00 & 0,20 & $\mathbf{0 , 6 1}$ & $-0,14$ \\
Q20 & 0,17 & 0,17 & 0,05 & $-0,02$ & $\mathbf{0 , 7 0}$ & 0,25 \\
Q21 & $-0,10$ & 0,07 & 0,09 & 0,18 & $\mathbf{0 , 4 8}$ & 0,38 \\
Q22 & $-0,01$ & $-0,31$ & 0,04 & $-0,41$ & 0,18 & $\mathbf{0 , 5 7}$ \\
Q23 & 0,05 & 0,17 & 0,08 & 0,15 & $-0,21$ & $\mathbf{0 , 5 0}$ \\
Q24 & $-0,02$ & $-0,25$ & $-0,04$ & $-0,08$ & 0,10 & $\mathbf{0 , 5 8}$ \\
\hline Fo & & & &
\end{tabular}

Fonte: dados da pesquisa (2018).

Na tabela 3, considerando o critério da significância prática, o qual sugere que sejam consideradas as cargas fatoriais acima de “0,50” (MINGOTI, 2005, p. 110), foi possível destacar as variáveis significativas.

$\mathrm{O}$ fator 1 representa $27,58 \%$ da variabilidade total do conjunto de dados, com as seguintes variáveis significativas: Q1 ao Q4. O fator 2, que explica $9,45 \%$ da variabilidade total, temos as composições das variáveis: Q5 ao Q9. As variáveis Q10 ao Q13 foram significativas no fator 3 , com $8,22 \%$ de variabilidade total. $O$ fator $4(6,08 \%)$ foi composto pelo Q14 ao Q16, fator $5(5,36 \%)$ pelo Q17 ao Q21, e por último o fator $6(4,54 \%)$ pelo Q22 ao Q24.

\subsection{PERFIL DO ENTREVISTADO}

Com relação ao perfil sociodemográfico dos entrevistados, serão destacados os seguintes pontos: gênero, faixa etária, estado civil, grau de escolaridade, renda familiar, ótica que costuma comprar e o município no qual residem, conforme tabela 4 . 


\section{Tabela 4 - Perfil dos clientes}

\begin{tabular}{|c|c|c|c|}
\hline \multicolumn{2}{|c|}{ Perfil do entrevistado } & Frequência absoluta & $\%$ \\
\hline \multirow{2}{*}{ Sexo } & Feminino & 112 & 53,33 \\
\hline & Masculino & 98 & 46,67 \\
\hline \multirow{5}{*}{ Faixa etária } & $18-29$ anos & 142 & 67,62 \\
\hline & $30-39$ anos & 37 & 17,62 \\
\hline & $40-49$ anos & 24 & 11,43 \\
\hline & $50-59$ anos & 4 & 1,90 \\
\hline & Acima de 59 anos & 3 & 1,43 \\
\hline \multirow{3}{*}{ Estado civil } & Solteiro & 131 & 62,38 \\
\hline & Casado & 66 & 31,43 \\
\hline & Divorciado & 13 & 6,19 \\
\hline \multirow{4}{*}{ Grau de escolaridade } & Ensino fundamental & 11 & 5,24 \\
\hline & Ensino médio & 56 & 26,66 \\
\hline & Ensino Superior & 101 & 48,10 \\
\hline & Pós-Graduação & 42 & 20,00 \\
\hline \multirow{5}{*}{ Renda familiar } & Menos de $\mathrm{R} \$ 880,00$ & 26 & 12,38 \\
\hline & $\begin{array}{c}\text { Entre } \mathrm{R} \$ 880,00 \text { e } \mathrm{R} \$ \\
3.000,00\end{array}$ & 95 & 45,24 \\
\hline & $\begin{array}{c}\text { Entre } \mathrm{R} \$ 3.001,00 \text { e } \mathrm{R} \$ \\
5.000,00\end{array}$ & 44 & 20,95 \\
\hline & $\begin{array}{c}\text { Entre } \mathrm{R} \$ 5.001,00 \text { e } \mathrm{R} \$ \\
10.000,00\end{array}$ & 31 & 14,76 \\
\hline & Mais de R\$10.00,00 & 14 & 6,67 \\
\hline \multirow{7}{*}{$\begin{array}{l}\text { Ótica costuma } \\
\text { comprar }\end{array}$} & Agraciosa & 64 & 30,48 \\
\hline & Clinótica & 50 & 23,81 \\
\hline & Luciano Ótica & 30 & 14,29 \\
\hline & Luxe Ótica & 26 & 12,38 \\
\hline & Aquino & 21 & 10,00 \\
\hline & Ótica Diniz & 19 & 9,04 \\
\hline & Total & 210 & 100,00 \\
\hline
\end{tabular}

Fonte: dados da pesquisa (2018).

\subsection{TESTE T DE STUDENT}

Por meio do teste $t$ de Student, para um nível de significância de 5\%, temos evidências de diferença estatística do estado civil com o grau de concordância dos itens 6 "Eu utilizo, frequentemente, a rede social Instagram", 8 "Eu utilizo, frequentemente, a rede social Twitter", 11 "Eu, frequentemente, compro via internet" e 24 "Eu sempre consigo me controlar quando sinto impulso de comprar algum produto".

No item em que o solteiro apresentou maior nível de concordância sobre os quesitos 6 , 8 e 11 , exceto no item 24 , no qual o casado apre- sentou maior grau de concordância. Os resultados obtidos condizem com a visão de Kotler e Keller (2006) de que buscam justificar o controle do impulso de comprar por parte dos consumidores cujo estado civil é casado, pois, segundo os autores, a família de procriação (cônjuge e filhos), influência mais diretamente no comportamento de compra, uma vez que existe um contato diário significativo o qual pode levá-lo a pensar mais antes de tomar uma decisão. Segundo Churchill e Peter (2000) essa tomada de decisão está diretamente ligada ao grau de im- 
portância que a compra possui em determinado momento, sendo assim o consumidor pode vir a adquirir um produto de acordo com a representatividade que ele possui e não por seu valor.

Por meio do teste $t$ de Student, para um nível de significância de 5\%, temos evidências de diferença estatística do nível de escolaridade com o grau de concordância dos itens 1 "Eu acesso as redes sociais com frequência", 2 "Eu costumo acessar as redes sociais de diferentes locais", 3 "Eu costumo acessar as redes sociais pelos dispositivos móveis", 4 "Eu costumo acessar as redes sociais pelos dispositivos fixos", 5 "Eu utilizo, frequentemente, a rede social Facebook", 7 "Eu utilizo, frequentemente, a rede social Whatsapp.", 10 "Eu já adquiri bens via Internet" e 22 "Eu compro nas óticas somente quando há necessidade".

No item em que os clientes com ensino superior apresentaram maior nível de concordância sobre todos os quesitos mencionados, exceto no item 22, em que os entrevistados com ensino fundamental ou médio apresentaram maior grau de concordância, os resultados obtidos coincidem com a visão de Morgado (2003) de que o consumidor online tem nível socioeconômico superior, valoriza mais a con- veniência, tem maior tendência à inovação, menor orientação experimental, conhece mais o idioma inglês, possui mais bens digitais, tem maior envolvimento com a internet, acredita em uma utilidade maior para a internet e acha importante comprar sem sair de casas. Logo, os consumidores com ensino superior têm um estilo de vida agitado, o que o leva a buscar meios alternativos de suprir suas necessidades, como o consumo virtual, uma vez que gera uma maior comodidade.

\subsection{RESULTADOS}

Nos aspectos gerais, relacionados às redes sociais (Whatsapp e Facebook), obteve um percentual com alto grau de concordância com relação ao acesso com frequência às redes sociais, sendo realizado em diferentes locais e por meio dos dispositivos móveis, conforme o gráfico 1. Isso corrobora uma pesquisa realizada pelo Comscore (2015), que apontou um alto crescimento dos brasileiros online em que 38,8 milhões de pessoas no país acessam as redes sociais mediante smartphone e tablets. Além de gastarem em torno de 650 horas por mês, nas redes sociais.

Gráfico 1 - Aspectos gerais relacionados às redes sociais

\begin{tabular}{|c|c|c|c|c|c|}
\hline \multirow{7}{*}{$\%$} & $\begin{array}{l}90 \\
60 \\
30\end{array}$ & & & & \\
\hline & 0 & $\begin{array}{l}\text { Eu acesso as } \\
\text { redes sociais } \\
\text { com } \\
\text { frequência. }\end{array}$ & $\begin{array}{l}\text { Eu costumo } \\
\text { acessar as } \\
\text { redes sociais } \\
\text { de diferentes } \\
\text { locais. }\end{array}$ & $\begin{array}{c}\text { Eu Costumo } \\
\text { acessar as } \\
\text { redes sociais } \\
\text { através dos } \\
\text { dispositivos } \\
\text { móveis. }\end{array}$ & $\begin{array}{c}\text { Eu costumo } \\
\text { acessar as } \\
\text { redes sociais } \\
\text { através dos } \\
\text { dispositivos } \\
\text { fixos. }\end{array}$ \\
\hline & Discordo totalmente & 2,38 & 3,81 & 4,29 & 13,33 \\
\hline & Discordo parcialmente & 2,38 & 5,24 & 1,43 & 9,05 \\
\hline & Indiferente & 4,76 & 7,15 & 3,33 & 10,00 \\
\hline & Concordo parcialmente & 15,24 & 11,90 & 8,10 & 17,62 \\
\hline & Concordo totalmente & 75,24 & 71,90 & 82,85 & 50,00 \\
\hline
\end{tabular}

Fonte: dados da pesquisa (2018). 
Sobre a frequência dos tipos de redes sociais utilizadas pelos respondentes, avaliando o nível de concordância e somando o concordo parcialmente e totalmente, temos o Whatsapp $(89,53 \%)$ e Facebook $(87,62 \%)$ como principais mídias sociais utilizadas pelos clientes de óticas, conforme demonstra o gráfico 2 . Interessante notar que, apesar de o WhatsApp ser mais utilizado pelos clientes, a rede social Facebook, segundo a pesquisa realizada pela Comscore (2015), continua sendo a líder em números de usuário, pois cerca de $78 \%$ do tempo é gasto nela.
$11,90 \%$ concordaram total e parcialmente, respectivamente com relação a ter costume de seguir perfil e Fan Page das óticas nas redes sociais. Enquanto curtir postagens das óticas nas redes sociais apresentou o seguinte resultado: discordo totalmente $(26,19 \%)$; discordo parcialmente $(14,76 \%)$; indiferente $(13,33 \%)$; concordo parcialmente $(13,33 \%)$ e concordo totalmente $(32,39 \%)$. Esses resultados condizem com a visão de Morgado (2003) ao explicar que o consumidor online valoriza mais a conveniência, tem maior tendência à inovação,

Gráfico 2 - Aspectos relacionados à frequência dos tipos de redes sociais utilizadas

\begin{tabular}{|l|l|c|c|c|c|}
\hline \multicolumn{1}{|c|}{60} & & & \\
\hline
\end{tabular}

Fonte: dados da pesquisa (2018).

O gráfico 3, a seguir, avalia o nível de concordância ao qual somando o concordo parcialmente e totalmente, temos que $66,19 \%$ já adquiram bens via Internet; entretanto, com relação a, frequentemente, comprar via internet, temos a seguinte distribuição dos resultados: discordo totalmente $(28,10 \%)$; discordo parcialmente $(12,38 \%)$; indiferente $(14,29 \%)$; concordo parcialmente $(20,00 \%)$ e concordo totalmente $(25,23 \%)$.

De acordo com os dados, 40,95\% e menor aversão ao risco e menor orientação experimental (não necessita ver e tocar no produto antes de comprá-lo), está há mais tempo, utilizando a internet, acessa de vários locais, confia mais na segurança da rede e a vê como uma mídia mais divertida e útil. 
Gráfico 3 - Aspectos relacionados a compras em redes sociais e postagens de publicações óticas em redes sociais

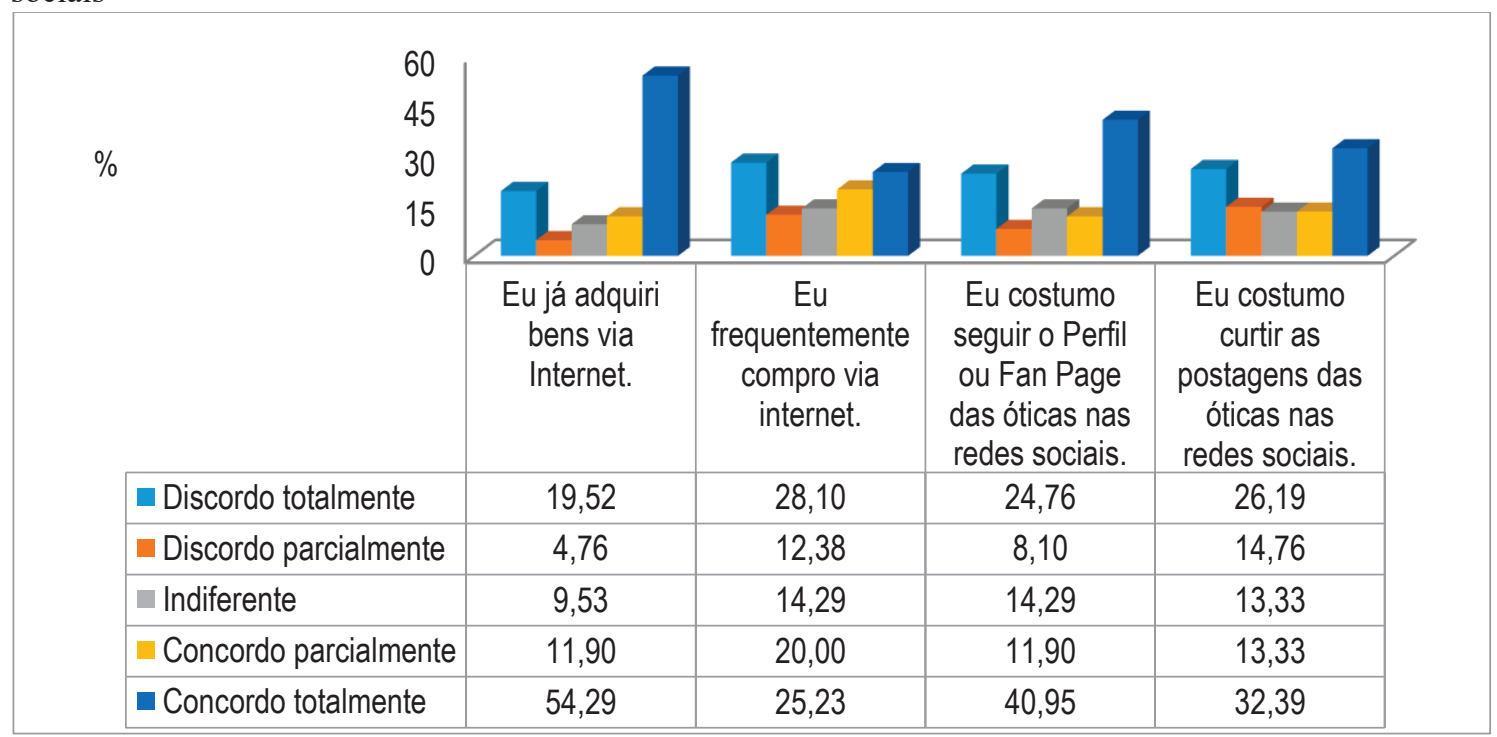

Fonte: dados da pesquisa (2018).

O gráfico 4 apresenta os resultados a respeito das seguintes afirmações: sentir-se influenciado adquirir algum bem a partir da visualização dele nas redes sociais, temos que $50,00 \%$ e $14,29 \%$ responderam que concordam totalmente e parcialmente, respectivamente, enquanto indiferente, discordo parcialmente e discordo totalmente houve os seguintes percentuais: $12,85 \%$, $10,48 \%$ e $12,38 \%$.

Já na afirmação sentir-se influenciado comprar um bem ao visualizá-lo nas redes sociais, temos que $47,63 \%$ e $19,52 \%$ responderam concorda totalmente e parcialmente, respectivamente, enquanto indiferente, discordo parcialmente e discordo totalmente teve os seguintes percentuais: $13,81 \%, 9,52 \%$ e $9,52 \%$.

Por último, obteve-se a afirmação de sentir-se influenciado comprar quando a postagem indica uma liquidação, constatou-se que $41,43 \%$ e $20,00 \%$ responderam concorda totalmente e parcialmente, respectivamente, enquanto indiferente, discordo parcialmente e discordo totalmente teve os seguintes percentuais: $13,33 \%, 10,48 \%$ e $14,76 \%$. Nesse ponto, os resultados condizem com a visão de Caro (2005) de que os consumidores online buscam de forma consciente por produtos de alta qua- lidade, marca, preços que correspondem a qualidade do produto e novidades contendo valores pessoais voltados para a satisfação consigo mesmo e à segurança. Corroborando com Caro (2005), Ladeira (2000) explica que a economia de tempo, a variedade de opções, a qualidade das informações que podem ser vistas na tela do computador e a diversão são os principais pontos de atração do uso da internet como veículo de compra. 
Gráfico 4 - Aspectos relacionados à influência de compras pela internet

\begin{tabular}{|c|c|c|c|}
\hline \multirow[t]{5}{*}{50} & & & \\
\hline & & & \\
\hline & & & \\
\hline & & & \\
\hline & $\begin{array}{c}\text { Eu me sinto } \\
\text { influenciado (a) a } \\
\text { adquirir algum bem a } \\
\text { partir da visualização } \\
\text { dele nas redes } \\
\text { sociais. }\end{array}$ & $\begin{array}{c}\text { Eu me sinto } \\
\text { intencionado (a) a } \\
\text { comprar um bem ao } \\
\text { visualizá-lo nas redes } \\
\text { sociais. }\end{array}$ & $\begin{array}{c}\text { Eu me sinto } \\
\text { influenciado (a) a } \\
\text { comprar quando a } \\
\text { postagem indica uma } \\
\text { liquidação. }\end{array}$ \\
\hline Discordo totalmente & 12,38 & 9,52 & 14,76 \\
\hline Discordo parcialmente & 10,48 & 9,52 & 10,48 \\
\hline Indiferente & 12,85 & 13,81 & 13,33 \\
\hline Concordo parcialmente & 14,29 & 19,52 & 20,00 \\
\hline Concordo totalmente & 50,00 & 47,63 & 41,43 \\
\hline
\end{tabular}

Fonte: dados da pesquisa (2018).

O gráfico 5 expressa os aspectos relacionados a influências de compras, no qual foi avaliado o nível de concordância somando o concordo parcialmente e totalmente, temos a qualidade $(92,85 \%)$ e o preço $(73,33 \%)$ como principais pontos levados em consideração na hora da compra, seguido de marcas $(61,43 \%)$, propagandas $(60,00 \%)$ e indicação de familiares e amigos $(58,57 \%)$. Esses resultados condizem com a perspectiva de Churchill e Peter (2000) de que os produtos que apresentam alta qualidade, exercem uma forte influência uma vez que são associados ao alto valor.

Kotler e Keller (2006), por sua vez, afirmam que os consumidores são influenciados pelas marca por buscarem nelas elementos compatíveis com sua personalidade e com sua autoimagem real (como essa pessoa se vê). No que diz respeito às influências exercidas pelas propagandas, de acordo com Churchill e Peter (2000) isso ocorre devido às suas mensagens que lembram os consumidores de que eles têm um problema e que só o produto deles pode solucioná-lo. A comunicação online também tem colaborado para que isso aconteça de forma mais intensiva, pois ela tem proporcionado um maior envolvimento dos consumidores com a compra ao buscarem, cada vez mais, informações sobre os produtos. 
Gráfico 5 - Aspectos relacionados a influências de compras

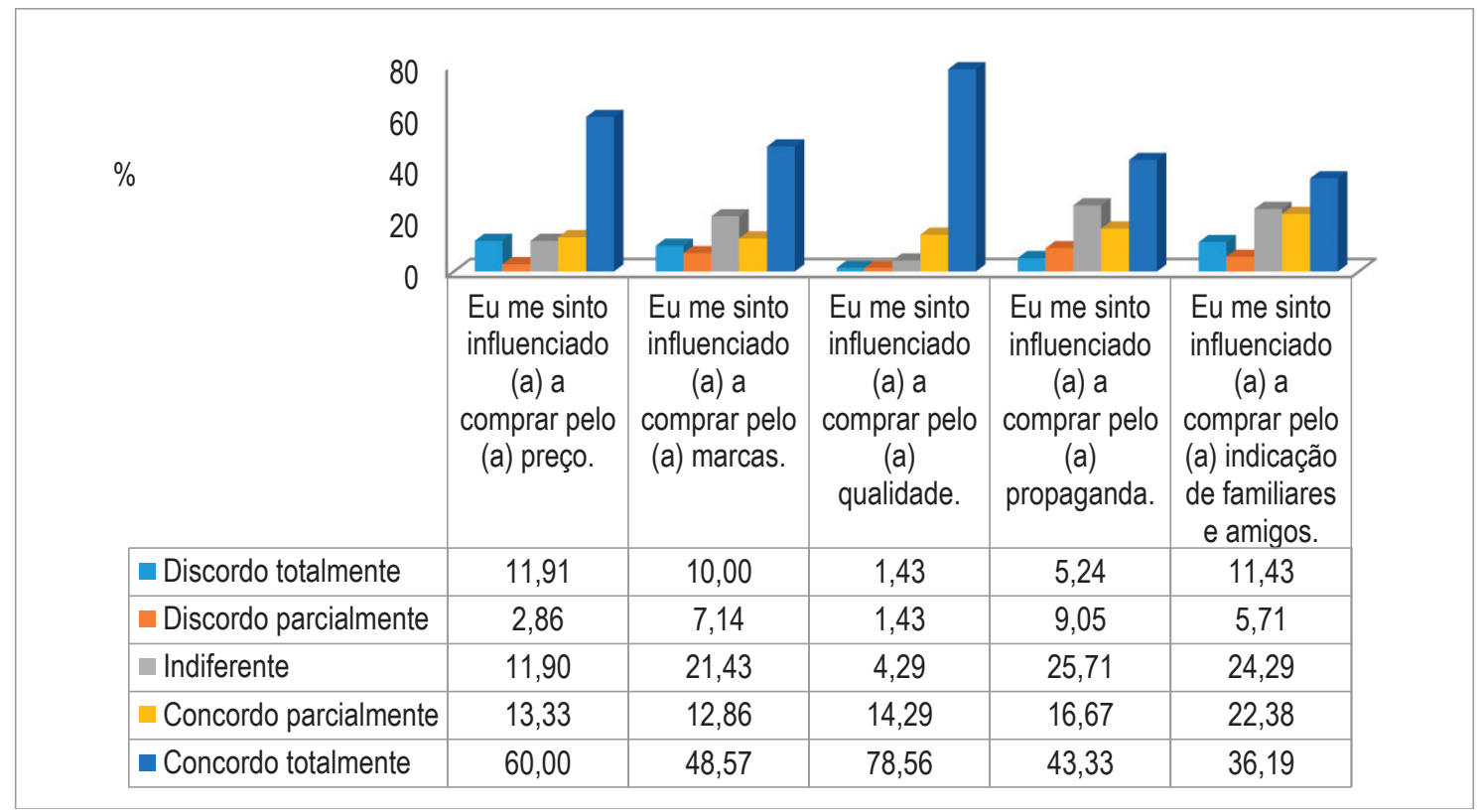

Fonte: dados da pesquisa (2018).

Com relação às influências exercidas pelos familiares e amigos, Kotler e Keller (2006) defendem que esse resultado se dá em consequência do convívio, pois, geralmente, os grupos de referência (família, amigos, colegas de trabalho) não dizem o que o consumidor deve fazer, em vez disso, influenciam-nos por meio de conversas, recomendações, sugestões e solicitações. Corroborando os autores Churchill e Peter (2000), afirmam que os grupos de referência exercem influênciais no consumidor por intermédio do comportamento, dos sentimentos e pensamentos.

O gráfico 6, apresenta os resultados a saber, na afirmação compro nas óticas somente quando há necessidade; $52,39 \%$ e $11,90 \%$ responderam concordar totalmente e parcialmente, respectivamente, enquanto indiferente, discordo parcialmente e discordo totalmente dos seguintes percentuais: $7,14 \%, 5,71 \%$ e $22,86 \%$.

Já na afirmação, quando sinto vontade de comprar algum produto eu sempre efetuo a compra, temos que $34,29 \%$ e $12,85 \%$ responderam concordar totalmente e parcialmente, respectivamente, enquanto que indiferente, discordo parcialmente e discordo totalmente os seguintes percentuais: $21,43 \%, 14,29 \%$ e $17,14 \%$.
Por último, temos a afirmação sempre consigo me controlar quando sinto impulso de comprar algum produto, temos que $36,66 \%$ e $16,19 \%$ responderam concordar totalmente e parcialmente, respectivamente, enquanto indiferente, discordo parcialmente e discordo totalmente dos seguintes percentuais: $15,24 \%$, $11,43 \%$ e $20,48 \%$. Foi possível notar um fato curioso a respeito da compra nas óticas somente por necessidade, apesar de 52,39\% terem concordado com essa afirmação, 22,86\% discordaram completamente, o que nos leva a compreender melhor que a busca por outros produtos existentes nesse tipo de negócio é uma realidade atual, corroborando esses resultados Churchill e Peter (2000) afirmam que a tomada de decisão está diretamente ligada ao grau de importância que a compra possui em determinado momento. Sendo assim, o consumidor pode vir a adquirir um produto de acordo com a representatividade que ele possui e não por seu valor. 
Gráfico 6 - Outros aspectos relacionados a influências de compras

\begin{tabular}{|l|c|c|c|}
\multicolumn{1}{|c|}{$\begin{array}{r}60 \\
30 \\
15\end{array}$} \\
0 & $\begin{array}{c}\text { Eu compro nas } \\
\text { óticas somente } \\
\text { quando há } \\
\text { necessidade. }\end{array}$ & $\begin{array}{c}\text { Quando eu sinto } \\
\text { vontade de } \\
\text { comprar algum } \\
\text { produto eu sempre } \\
\text { efetuo a compra. }\end{array}$ & $\begin{array}{c}\text { Eu sempre consigo } \\
\text { me controlar } \\
\text { quando sinto } \\
\text { impulso de } \\
\text { comprar algum } \\
\text { produto. }\end{array}$ \\
\hline - Discordo totalmente & 22,86 & 17,14 & 20,48 \\
\hline Discordo parcialmente & 5,71 & 14,29 & 11,43 \\
\hline Indiferente & 7,14 & 21,43 & 15,24 \\
\hline Concordo parcialmente & 11,90 & 12,85 & 16,19 \\
\hline - Concordo totalmente & 52,39 & 34,29 & 36,66 \\
\hline
\end{tabular}

Fonte: dados da pesquisa (2018).

A tabela 5, a seguir, apresenta os valores da comparação dos 6 fatores que foram encontrados nos questionários aplicados.

\begin{tabular}{cccccccccc}
\hline \multicolumn{10}{c}{ Tabela 5 - Comparação dos fatores } \\
\hline Fator & Mínimo & Máximo & $\mathbf{2 5 \%}$ & Mediana & $\mathbf{7 5 \%}$ & Média & DP & CV & Valor-p \\
\hline 1 & 1,00 & 5,00 & 4,00 & 4,75 & 5,00 & 4,37 & 0,82 & 18,77 & \\
2 & 1,00 & 5,00 & 2,60 & 3,40 & 3,80 & 3,27 & 0,83 & 25,47 & \\
3 & 1,00 & 5,00 & 2,50 & 3,00 & 4,25 & 3,31 & 1,10 & 33,09 & \multirow{2}{*}{$0,000^{*}$} \\
4 & 1,00 & 5,00 & 3,00 & 4,00 & 5,00 & 3,76 & 1,20 & 31,97 & \\
5 & 1,60 & 5,00 & 3,60 & 4,00 & 4,60 & 4,01 & 0,73 & 18,08 & \\
6 & 1,00 & 5,00 & 2,67 & 3,67 & 4,00 & 3,45 & 0,90 & 26,06 & \\
\hline
\end{tabular}

Fonte: dados da pesquisa (2018). (DP: Desvio Padrão CV: Coeficiente de Variação).

\section{CONCLUSÕES, SUGESTÕES E RECOMENDAÇÕES}

A globalização e a explosão das empresas ponto-com marcaram o início de uma nova era na internet que, segundo Anandarajan, Thompson e Simmers (2006), geraram a possibilidade de ampliar e aprimorar a velocidade das transações de seus usuários, encurtando distâncias entre a organização e seus clientes, além de ter possibilitado o surgimento de novos canais de compra, os quais estão dispostos a suprir os desejos e as necessidades dos consumidores. Nesse paradigma, este estudo procurou inves- tigar as influências das redes sociais no processo de decisão de compra dos consumidores de óticas mediante identificação das variáveis - qualidade do produto, preço, marca, propaganda e indicação de familiares e amigos - que influenciam na tomada de decisão. Para tal, em primeira instância, foi necessária uma breve revisão da literatura, descrevendo o processo evolutivo da web. Logo em seguida, foram extraídas as variáveis destacadas pelos autores no referencial teórico e suas descrições das redes sociais que foram utilizadas, com maior frequência, no período de coleta desta pesquisa. E, para finalizar, realizou-se uma análise fato- 
rial dos conjuntos de variáveis estudadas acerca do comportamento do consumidor no processo de decisão de compras e o comportamento do consumidor online.

Com base nos resultados, foi possível notar o perfil sociodemográfico dos consumidores, a existência de uma diversidade nas questões de caráter social, como renda familiar, estado civil, grau de escolaridade, bem como as características pessoais de sexo e idade. O que demonstra que fatores como o estado civil "solteiro" $62,38 \%$, o grau de escolaridade "ensino superior" $48,10 \%$, idade "faixa etária 18-29 anos" 67,62 e condição social "renda familiar entre R\$ 880,00 e R \$ 3.000,00" 45,24\% influenciam tanto na escolha da ótica, como nos seus hábitos de acesso às redes sociais. De acordo com os dados da pesquisa, o consumidor online valoriza mais a conveniência, tem maior tendência à inovação, menor aversão ao risco e menor orientação experimental e está, há mais tempo, utilizando a internet, acessa-a de vários locais, confia mais na segurança da rede e a vê como uma mídia mais divertida e útil.

Dessa forma, em consenso com todos os dados coletados e aos aspectos obervados, conclui-se que o objetivo da pesquisa foi alcançado ao identificar e analisar as formas que as redes sociais influenciam no processo de tomada de decisão dos consumidores, por meio de variáveis que vão desde os hábitos de acesso, frequência, vizualização, liquidação, qualidade do produto, preço, propaganda, marca, indicação de familiares e amigos, necessidade e rede social mais utilizada.

Os resultados deste estudo mostram que a questão-problema foi considerada afirmativa quando questionado "Será que as redes sociais influenciam positivamente no processo de decisão de compra do consumidor em óticas?", segundo Kotler e Keller (2006, p. 66), associam-se os fatores que influenciam no processo de tomada de decisão de compra do consumidor, porém, tornando mais divertida a aquisição, por meio das redes sociais (KOTLER; KELLER, 2006). Já para Solomon (2016), algumas estratégias relacionadas a promoções de produtos incluem consumidores (indivíduos comuns) cujas atividades de consumo oferecem, relativamente, uma forte influência no processo de decisão de compra.

Logo, os resultados autorizam responder ao questionamento "Será que as redes sociais influenciam, positivamente, no processo de decisão de compra do consumidor em óticas?", que as redes sociais influenciam no processo de tomada de decisão dos consumidores, uma vez que, por meio da vizualização de um produto no feed das redes sociais, o consumidor sofre estimulos e, consequentemente, o desejo de ter aquele determinado produto é gerado. Esta pesquisa se mostrou importante tanto para os usuários das redes sociais, como para as óticas e para a academia, no sentido de que um conhecimento sobre as mudanças ocorridas no comportamento do consumidor diante desse novo canal de comunicação. Colaborando, assim, para que as óticas desenvolvam estratégias voltadas para essas novas mídias e abrindo espaço para a relização de novas pesquisas que se aprofundem nelas.

Diante da análise dos dados obtidos nesta pesquisa, como sugestões principais para as óticas parte do estudo, podem-se destacar o uso das redes sociais não apenas como veículo para promover seus produtos, mas também, como um canal para sugestões, esclarecimentos de dúvidas, reservas de produto ou mesmo efetuar a própria compra. É importante frisar que essas medidas aparentemente simples, servem de diferencial diante da realidade do mercado local. O estudo traz evidências de que as redes sociais influenciam, de forma significativa, sobre o comportamento dos consumidores de óticas. Diante desse resultado, de acordo com os dados, 64,29\% dos respondentes, concordam parcialmente e totalmente que "sentem influenciados em adquirir algum bem a partir da visualização nas redes sociais", além disso, 61,43\% dos respondentes concordam parcialmente e totalmente que "sentem influenciados a comprar quando a postagem indica uma liquidação". Portanto, é fundamental que seja dada uma maior atenção ao canal de comunicação, uma 
vez que ele pode vir a ser um fator decisivo no processo de compra, para tanto, ao realizar uma busca por informações de um determinado produto, o consumidor avalia desde a disponibilidade do produto até as marcas, dependendo do tipo de avaliação que ele realiza, a compra pode ser efetuada ou não.

Esta temática, por ser de caráter recente, tem trazido à tona questões que levam as empresas a assumirem uma postura diante das mudanças trazidas por essas novas mídias, e isso requer um conhecimento específico, como também pessoas capacitadas para lidar com novas mídias. Em caráter geral, recomenda-se a realização do aprofundamento deste estudo, considerando um universo maior, no caso de abranger todas as óticas da cidade de Pau dos Ferros ou com o foco nas estratégias que podem ser desenvolvidas pelas óticas com base no perfil do consumidor online, ou, até mesmo, outras variáveis mais específicas que influenciam no processo de compra dos consumidores desse segmento com a elaboração de mais pesquisas e artigos científicos, para que, dessa forma, o mercado local conheça melhor seu público e realize estratégias voltadas para ele, com elementos diferenciados para se destacarem de seus concorrentes, pois o mercado é mutável e requer das organizações um aperfeiçoamento constante.

\section{REFERÊNCIAS}

AGHAEI, Sareh; NEMATBAKHSH, Mohammad Ali; FARSANI, Hadi Khosravi. Evolution of the world wide web: From web 1.0 to web 4.0. International Journal of Web \& Semantic Technology, v. 3, n. 1, p. 1-10, 2012.

ANANDARAJAN, M.; THOMPSON, T.; SIMMERS, C. The internet and workplace transformation: advences in Management Information Systems. New York: M.E. Sharpe, 2006.

BERNERS-LEE, Tim. Tejiendo la red: el inventor del World Wide Web nos descubre su origen. [S.l.: s.n.], 2000.
CARO, A. Fatores críticos no comportamento do consumidor online. 2005. Dissertação (Mestrado em Administração) - Programa de Pós-Graduação em Administração, Departamento de Administração da Faculdade de Economia, administração e Contabilidade da Universidade de São Paulo, São Paulo, 2005.

CHURCHILL, J. G.; PETER, J. P. Marketing: Criando valor para os clientes. São Paulo: Saraiva, 2000.

COMSCORE. Estudo da Comscore: Brazil Digital Future in Focus 2014 está disponível. 2015. Disponível em: http://www. comscore.com/por/Imprensa-e-eventos/Press-Releases/2014/5/Estudo-da-comScore-Brazil-Digital-Future-in-Focus-2014-esta-disponivel. Acesso em: 28 out. 2018.

FERREIRA JÚNIOR, Sílvio; BAPTISTA, Antonio Jose Medina dos Santos; LIMA, Joao Eustaquio de. A modernização agropecuária nas microrregiões do Estado de Minas Gerais. Brazilian Journal of Rural Economy and Sociology (Revista de Economia e Sociologia Rural-RESR), v. 42, n. 1346-2016105086, p. 73-89, 2004.

FOXALL, G. R. O processo decisório de consumidor: processo, nível e estilo. In: BAKER, M. J. Administração de Marketing. Rio de Janeiro: Elsevier, 2005. p. 603.

GIGLIO, Ernesto Michelangelo. Comportamento do Consumidor. 3. ed. São Paulo: Cengage Learning, 2005.

HAIR JUNIOR, J. F. et al. Análise multivariada de dados. 6. ed. Porto Alegre: Bookman, 2009.

BAXTER, James G. Implementing Web 2.0 tools in organisations. Emerald Insingth, v. 21, p. 2-5, 2014.

KABADAYI, S.; PRICE, K. Consumer brand 
engagement on facebook: linking and commeting behaviors. Journal of Reserarch in interactive Marketing, v. 8, n. 3, p. 203-223, 2014.

KOLLMANN, T. Grundlagen des Web 1.0, Web 2.0, Web 3.0 und Web 4.0. Handbuch Digitale Wirtschaft, p. 1-23, 2018.

KOTLER, P.; KELLER, K. L. Administração de Marketing. São Paulo: Pearson Prentice Hall, 2006.

KOTLER, Philip; KARTAJAYA, Hermawan; SETIAWAN, Iwan. Marketing 4.0: do tradicional ao digital. [S.l.]: Sextante, 2017.

LADEIRA, R. Razões que levam consumidores brasileiros a comprar pela internet. 2000 . Tese (Doutorado em Administração) - Programa de Pós-Graduação em Administração, Departamento de Administração da faculdade de Economia, Administração e Contabilidade da Universidade de São Paulo, São Paulo, 2000.

LIKERT, R. A technique for the measurement of attitudes. Archives of Psychology. New York: R. S. Woodworth, 1932.

MAINIERI, T.; RIBEIRO, E. A comunicação pública como processo para o exercício da cidadania: o papel das mídias sociais na sociedade democratica. Revista Organicom, v. 8, n. 14, 2011.

MINGOTI, S. A. Análise de dados através de métodos de estatística multivariada. Belo Horizonte: UFMG, 2005.

MORGADO, M. G. Comportamento do Consumidor On-line: Perfil, uso da internet e atitudes. 2003. Dissertação (Doutorado em Administração) - Programa de Pós-Graduação em Administração, Fundação Getúlio Vargas, Escola de Administração de Empresas de São Paulo, São Paulo, 2003.

RECUERO, R. Redes Sociais na Internet.
Porto Alegre: Sulina, 2009.

REEDY, J.; SCHULLO, S. Marketing Digital. [S.l.: s.n.], 2007.

ROCK CONTENT. Social Media Trends. 2018. Disponível em: https://inteligencia.rockcontent.com/social-media-trends-2018/. Acesso em: 23 mar. 2018

SAAD, E.; ABREU, A.; RAMOS, D. O estudos das redes sociais na comunicação digital: é preciso usar metáforas? Estudos de Comunicação, n. 6, p. 221-225, 2009.

SEBRAE - Serviço Brasileiro de Apoio às Microempresas. Empresas-Sebrae, e. pequenas. 2017. Disponível em: www.sebrae.com. br. Acesso em: 23 mar. 2018.

SOLOMON, M. R. O Comportamento do consumidor: comprando, possuindo e sendo. Porto Alegre: Bookman, 2016.

SCHULTZ, D.; PELTIER, J. Social media's slippery slope: challenges opportunities and future research directions. Journal of Rearch in Interative Marketing, v. 7, n. 2, p. 89-99, 2013.

SHARMA, SMITA; REHMAN, Asad. A Comparative study of use of Social Networking Sites as a Marketing Communication tool across selected Sectors. LBS Journal of Management \& Research, v. 11, n. 2, p. 28-39, 2013.

TREIN, D.; SCHLEMMER, E. Projetos de aprendizagem no contexto da Web 2.0: possibilidades para a prática pedagógica. In: SEMINÁRIO WEBCURRÍCULO PUC-SP, 1., 2008, São Paulo. Anais [...]. São Paulo, 2008. Disponível em: http:// gpedunisinos.wordpress.com/ producao/artigos/. Acesso em: 23 mar. 2018. 